\title{
Model Pemasaran Digital Marketing dalam Meningkatkan Volume Penjualan pada UMKM Kota Semarang
}

\author{
Leonardo Budi Hasiholan, Dheasey Amboningtyas \\ Universitas Pandanaran, Indonesia \\ Email corresponding author: leonardobudihas@yahoo.com/dheasey@unpand.ac.id
}

\begin{abstract}
ABSTRAK
Tujuan Penelitian ini ingin mengetahui model pemasaran digital marketing dalam meningkatkan volume penjualan pada UMKM Kota Semarang. Perkembangan teknologi informasi yang berkembang sangat pesat saat ini berpengaruh bagi masyarakat dalam mendukung berbagai kegiatan bisnis baik besar maupun kecil agar dapat dikenal secara global. Dampak yang paling nyata adalah selain dikenal juga dapat meningkatkan volume penjualan dan profit. Pemasaran online cocok untuk bisnis / bisnis yang baru. Tentu itu hemat biaya, karena tidak harus menempatkan produk / jasa, dapat dikontrol sendiri tanpa harus merekrut karyawan, waktu tanpa batas atau jam kerja, dan memiliki jangkauan pasar yang luas, karena pemasaran online didukung oleh kehadiran dari situs web. Digital Marketing adalah salah satu media pemasaran yang sangat besar manfaatnya. Yaitu, melaluisosial media (Facebook, Twitter, Instagram, WhatsApp, TikTok, dll). Penelitiaan ini menggunakan metode penelitiaan naturalistic dengan pendekatan data kualitatif. Studi Pustaka adalah teknik untuk mendapatkan data teoritis atau data sekunder dalam penelitian. Studi Pustaka dilakukan dengan mempelajari buku, literatur, dokumen resmi, catatan dan transkrip, yang terkait dengan penelitian.
\end{abstract}

Kata Kunci: Model pemasaran, digital marketing, volume penjualan, danpemasaran online

\section{PENDAHULUAN}

Era globalisasi yang ditandai dengan perkembangan teknologi termasuk teknologi internet (interconected Network) dimana, setiap orang dapat berkomunikasi dan menyampaikan informasi tidak terhalang oleh tempat dan waktu serta penyampainnya dapat dilakukan dengan mudah (Online). Di Indonesia sendiri perkembangan internet dan penggunannya terus bertambah dari tahun ketahun walaupun jika dibandingkan dengan negara lain masih ketinggalan. Perkembangan teknologi informasi sangat berkembang pesat. Berbagai kegiatan bisnis kecil sampai besar memanfaatkan perkembangan ini untuk menjalankan usahanya. Banyaknya competitor menjadi pertimbangan bagi para pengusaha untuk masuk dalam persaingan yang sangat ketat. Strategi pemasaran dan media yang tepat digunakan untuk bisa meraih pasar yang dituju sehingga volume penjualan selalu meningkat dan profit. Digital Marketing adalah salah satu media pemasaran yang saat ini sedang banyak diminati oleh masyarakat untuk medukung berbagai kegiatan yang dilakukan. Mereka sedikit demi sedikit mulai meninggalkan model pemasaran konvesional/tradisional beralih ke pemasaran modern yaitu digital marketing.

Dengan digital marketing komunikasi dan transaksi dapat dilakukan setiap waktu/real time dan bisa mengglobal atau mendunia. Dengan adanya jumlah pengguna sosial media membuat semakin bertambah membuka peluang bagi UMKM dalam mengembangkan sayapnya di pasaran saat ini hanya bermodalkan smartphone (Nugraha, 2017). Kegiatan komunikasi pemasaran yang terpadu, tidak lepas dari bauran promosi (promotional mix) yang ada. Bauran promosi terdiri dari periklanan (advertising), penjualan personal (personalselling), 
penjualan promosi (promotional selling), hubungan masyarakat (public relation), dan pemasaran langsung (direct marketing). Ada satu elemen yang masuk sebagai elemen bauran promosi ini, yaitu pemasaran digital (digital marketing). Untuk kelima elemen bauran promosi lainnya, keberadaanya masing-masing dan secara bersama-sama menunjang terciptanya suatu kegiatan komunikasi pemasaran yang efektif (Yoga \& Nurmahdi, 2018)

\section{METODE PENELITIAN}

Metode yang peneliti gunakan adalah metode naturalistik dengan pendekatan jenis data kualitatif. Hal ini dikarenakan, peneliti tidak membuktikan ataupun menolak hipotesis yang dibuat sebelum penelitian tetapi mengolah data dan mengalisis suatu masalah secara non numerik. Metode Kualitatif untuk menguji hipotesis/teori (Sugiyono, 2016). Untuk memperoleh dan mengumpulkan data dalam penelitian ini, penulis memperoleh data melalui: Penelitian Lapangan (Field Research) yang berupa (a) Observasi, (b) Kuesioner/angket, dan (c) Wawancara. Selainitujugadilakukan Penelitian Kepustakaan (Library Research).

\section{HASIL DAN PEMBAHASAN}

Pemasaran Digital memberikan implikasi yang menjangkau jauh terhadap kepentingan dari berbagai elemen yang berbeda dalam bauran untuk banyak pasar, mengenyampingkan bahwa apakah perusahaan berkecimpung secara langsung dalam transaksi e-commerce. Akibatnya, bauran pemasaran merupakan kerangka kerja yang berguna untuk menginformasikan pengembangan strategi. Pertama, pemasaran digital memberi kerangka kerja untuk membandingkan layanan yang ada dengan pesaing dan dapat juga digunakan sebagai mekanisme untuk menghasilkan alternatif pendekatan strategis. Mengutip dari Harwindra Yoga Prasetya dan Adi Nurmahdi, pemasaran digital (atau juga disebut pemasaran internet atau pemasaran online) diasosiasikan dengan pemasaran langsung karena perusahaan - perusahaan yang melakukan kegiatan pemasaran digital ini dapat memperpendek supply chain atau rantai pasokannya, dan tentunya dapat mengurangi biaya operasionalnya. Dengan mengurangi biaya operasional tentu saja akan berdampak positif baik bagi perusahaan dan bagi pengguna sebagai konsumen.

Nilai kinerja penjualan akan naik jika penggunaan digital marketing makin ditingkatkan pada UMKM di Kota Semarang. Hasil wawancara menunjukan bahwa dengan penggunaan fasilitas online dalam hal marketing, promosi dan transaksi akan meningkatkan nilai penjualan produk UMKM. Menurut Ferdinand (2006) dalam (Prabowo, 2018), menyatakan bahwa minat beli dapat diidentifikasi melalui indikator-indikator sebagai berikut:

1. Minat transaksional

2. Minat referensial

3. Minat preferensial

4. Minat eksploratif

Tingginya pengguna internet, pengguna sosial media, dan konten komersial yang sering dikunjungi dari hari ke hari melonjak naik, ini menunjukkan animo pengguna (user)untuk keperluan bisnisnya tergolong cukup tinggi. Namun tidak dibarengi dengan peningkatan pemanfaatan digital marketing yang benar di dunia usaha terutama usaha yang tergolong mikro. Dari hasil observasi, masih banyak ditemukan pengusaha sektor jenis usaha baru di UMKM Kota Semarangyangbelum familiar menggunakan media tersebut dengan alasan, belum mengetahui bahkan masih gaptek di tambah lagi ketidakpercayaan pada media tersebut. Dari berbagai media digital marketing terdapat media yang paling cocok untuk UMKM terutama usaha mikro yaitu enggament (Comment, Like, share) dan Kunjungan Toko (Visit 
Store). Dimanahaltersebut dapat mencapai ribuan bahkan jutaan konsumen dengan biaya sangat murah dan tertarget

\section{KESIMPULAN DAN SARAN}

Berdasarkan hasil penelitian maka dapat disimpulkan, bahwa terdapat pengaruh marketing digital terhadap kinerja penjualan produk UMKM di Kota Semarang. Model Pemasaran dengan menggunakan sarana modern saatini, mudah untuk dilakukan oleh user. Walaupun masih banyak yang belum mengetahui banyak tentang teknologi informasi.Hal yang paling utama dilakukan adalah membentuk pasar dengan mengumpulkan teman-teman yang sudah dipastikan menyukai produk kita dengan tujuan, mereka akan tetap memperhatikan apa yang kita sampaikan.E-mail juga dapat digunakan untuk menjangkau pasar dengan sebelumnya mengumpulkan email sebanyak mungkin, namun dengan cara yang baik artinya mendapatkan e-mail dengan kemauan user sendiri. Informasi yang dikirimkan sekaligus ke konsumen harus menggunakan pihak ke-3 yaitu yang direferensikan oleh para marketter.

Disarankan untuk meningkatkan penggunaan digital marketing agar pemasaran produk dapat meningkat sehingga target penjualan tiap bulannya dapat meningkat pula. Manfaat yang paling dirasakan adalah komunikasi denganpara pelanggan dan pemasok lebih intestif serta efektif dan efisien, karena dapat berkomunikasi langsung selama 24 jam/real time. Proses transaksi lebih mudah dan murah karena media komunikasi hanya mengeluarkan biaya pulsa untuk mendukung komunikasi. Media promosi yang paling baik karena bisa menampikan dan berbagi gambar lewat media ke komunitas dan masyarakat. Update informasi dapat dilakukan setiap waktu. Dan yang paling penting peningkatan volume penjualan rata-rata $100 \%$.

UMKM di Kota Semarang disarankan lebih mengoptimalkan perkembangan teknologi informasi yang ada dengan maksimal. Artinya, mulai melakukan inovasi-inovasi baru cara mempromosikan hasil karyanya agar lebih menarik dengan memanfaatkan social media yang ada agar peningkatan volume penjualan secara continue bisa meningkat dan berkembang

\section{DAFTAR PUSTAKA}

Budianto Apri (2016) Marketing Strategies Model with E-Commerce in Improving Market Area of SMEs in Rural District Ciamis, West Java Province, Indonesia.

Fisip, H. (2020, June). PROSIDING SLAMET RIYADI CONFERENCE ON PUBLIC ADMINISTRATION (SRIPA). In PROSIDING: SLAMET RIYADI CONFERENCE ON PUBLIC ADMINISTRATION (SRIPA) (Vol. 2, No. 1).

Kotler, Philip dan Gary Amstrong, 2004, Principles of Marketing, 10th Edition, Pearson Education Inc. Upper Saddle River, New Jersey.

Mahardika, E., \& Aji, G. G. 2018. Implementasi Komunikasi Pemasaran Digital Dalam Promosi Pariwisata (Studi Kasus Pada Kota Wisata Batu). Commercium, 2(2).

Nursatyo. 2018. Daya Tarik Pesan Komunikasi Pemasaran Di Media Sosial The Attractiveness of Marketing Communication Messages in Social Media. Universitas Nasional, 70-89.

Rangkuti, F. (2010). Analisis SWOT teknik membedah kasus bisnis, Gramedia Pustaka Umum, Jakarta.

Sherlin, I. 2016. Pengaruh inovasi produk dan kinerja pemasaran terhadap keunggulan bersaing. Jurnal Benefita, 1(3), 105-112.

Sunariani, N. N., Suryadinata, A. O., \& Mahaputra, I. I. R. 2017. Pemberdayaan usaha mikro kecil dan menengah (umkm) melalui program binaan di provinsi Bali. Jurnal Ilmiah Manajemen Dan Bisnis, 2(1). 
Syairozi, M. I., Pambudy, A. P., \& Yaskun, M. (2021). Analisis Penerapan Good Governance dalam Sistem Informasi Keuangan Daerah. Prosiding Penelitian Pendidikan dan Pengabdian 2021, 1(1), 49-59.

Sudarmanto, E., Fitriana, A., Malau, M., Nainggolan, C. D., Zunaidi, A., Manurung, S., ... \& Hidayat, G. (2021). PENGANGGARAN PERUSAHAAN.

Yoga, H., \& Nurmahdi, A. 2018. Pengaruh Kegiatan Pemasaran Digital dan Perilaku Online Konsumen Pada Peningkatan Kesadaran Konsumen dan Dampaknya Terhadap Keputusan Pembelian Via Website. Harwindra_yoga@yahoo.com

Zimmerer, Thomas W, dan Norman M. Scarborugh. (2004). Pengantar Kewirausahaan dan Manajemen Bisnis Kecil. Edisi Bahasa Indonesia. PT Indeks. Jakarta 